\title{
E-test versus agar dilution for antibiotic susceptibility testing of Helicobacter pylori: a comparison study
}

\author{
Muhammad Miftahussurur ${ }^{1,2^{*}{ }^{+}}$, Kartika Afrida Fauzia ${ }^{2,3{ }^{\dagger}}$, Iswan Abbas Nusi ${ }^{1}$, Poernomo Boedi Setiawan ${ }^{1}$, \\ Ari Fahrial Syam ${ }^{4}$, Langgeng Agung Waskito ${ }^{2,3}$, Dalla Doohan²,3, Neneng Ratnasari ${ }^{5}$, Ali Khomsan 6 , \\ I. Ketut Adnyana', Junko Akada ${ }^{3}$ and Yoshio Yamaoka 1,3,8,**
}

\begin{abstract}
Objective: For evaluating the antibiotic resistance of Helicobacter pylori, the agar dilution method is the gold standard; however, using this method in daily practice is laborious. E-test has been proposed to be an uncomplicated method. This study was aimed at validating the E-test and detecting the presence of any bias between the agar dilution method and E-test.

Results: The agar dilution method and E-test were performed using five antibiotics for 72 strains of $H$. pylori obtained from clinical patients in Indonesia. The E-test's results showed a higher prevalence of resistance to all the antibiotics tested but the difference was not significant. Results showed high essential agreement (>90.0\%) for all the antibiotics, but only $84.7 \%$ for metronidazole. The agreement for MIC value was acceptable for levofloxacin, clarithromycin, and metronidazole. For amoxicillin, it showed only fair agreement (0.25) by the Kappa analysis and significant difference by Passing-Bablok regression. Even though some discrepancies were found, the E-test has an acceptable agreement for levofloxacin, metronidazole, tetracycline, and clarithromycin but further confirmation may be necessary for amoxicillin.
\end{abstract}

Keywords: E-test, Agar dilution, Helicobacter pylori, Antibiotic susceptibility test

\section{Introduction}

Helicobacter pylori virulent strains being predominant in several regions thus $H$. pylori should always be treated regardless of the presence of symptoms [1]. However, antibiotic resistance caused in Helicobacter pylori eradication failure and the resistance rates widely vary around the world [2-4]. Recent hospital-based study in Japan

\footnotetext{
*Correspondence: muhammad-m@fk.unair.ac.id; yyamaoka@oita-u.ac.jp ${ }^{\dagger}$ Muhammad Miftahussurur and Kartika Afrida Fauzia contributed equally to this study

${ }^{1}$ Division of Gastroentero-Hepatology, Department of Internal Medicine, Faculty of Medicine-Dr. Soetomo Teaching Hospital, Universitas Airlangga, Jalan Mayjend Prof. Dr. Moestopo No. 6-8 Surabaya, Surabaya 60131 Indonesia

Full list of author information is available at the end of the article
}

reporting $48 \%$ of clarithromycin resistance [5] while our previous study in Indonesia reported a 9\% resistant rate [6]. Because of such differences, the Maastricht Consensus Report on H. pylori infection has stated that antibiotic susceptibility tests with periodic monitoring should be performed in each region to determine the most suitable therapy for a given population [2].

Given the importance of antibiotic susceptibility testing for $\mathrm{H}$. pylori, it is crucial to choose a testing method that delivers high accuracy and feasible for clinical settings. According to the Clinical and Laboratory Standards Institute (CLSI), direct measurement with the agar dilution method (ADM) is the gold standard for H. pylori [7]. However, ADM requires laborious preparation and may not cost and time-effective for daily

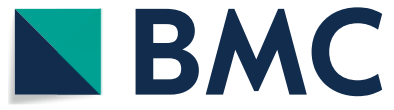

(C) The Author(s) 2020. This article is licensed under a Creative Commons Attribution 4.0 International License, which permits use, sharing adaptation, distribution and reproduction in any medium or format, as long as you give appropriate credit to the original author(s) and the source, provide a link to the Creative Commons licence, and indicate if changes were made. The images or other third party material in this article are included in the article's Creative Commons licence, unless indicated otherwise in a credit line to the material. If material is not included in the article's Creative Commons licence and your intended use is not permitted by statutory regulation or exceeds the permitted use, you will need to obtain permission directly from the copyright holder. To view a copy of this licence, visit http://creativeco mmons.org/licenses/by/4.0/. The Creative Commons Public Domain Dedication waiver (http://creativecommons.org/publicdomain/ zero/1.0/) applies to the data made available in this article, unless otherwise stated in a credit line to the data. 
clinical practices [8]. An alternative, relatively simple method is the E-test, which uses different concentrations of antibiotics in a single strip.

In the present study, we followed CLSI guideline EP-09 to compare the measurement procedures and estimate bias [9]. These methods have been applied in other studies, but rarely for $H$. pylori [10-13]. Thus, a study using isolates from the Indonesian population, an area with the variable prevalence and virulence type of $H$. pylori $[6,14]$ may provide another insight of the E-test reliability.

This study aimed to examine the susceptibility of Indonesian $H$. pylori isolates to five antibiotics (amoxicillin, clarithromycin, metronidazole, tetracycline, and levofloxacin), using ADM as the gold standard to validate the level of agreement and reliability of the E-test.

\section{Main text \\ Methods \\ Patients and H. pylori isolates}

We analyzed a total of 72 clinical $H$. pylori isolates obtained from adult dyspeptic patients as part of a nationwide survey in Indonesia and reference strain ATCC26695. Data for the E-test results for the 72 strains were published in our previous study [6]. Isolate storage and all the susceptibility tests were conducted at the Department of Environment and Preventive Medicine, Oita University Faculty of Medicine, Yufu, Japan.

All the patients from whom the isolates were obtained provided written informed consent, and the study protocol was approved by the Institutional Review Board or Ethics Committee of Dr. Cipto Mangunkusumo Teaching Hospital (Jakarta, Indonesia), Dr. Soetomo Teaching Hospital (Surabaya, Indonesia), Dr. Wahidin Sudirohusodo Teaching Hospital (Makassar, Indonesia), and Oita University Faculty of Medicine (Yufu, Japan).

\section{Antibiotic susceptibility testing by ADM and E-test}

The procedure for ADM followed the protocol described by CLSI $[7,15]$. Briefly, around $2 \mu \mathrm{L}$ of bacterial suspension with 0.5 McFarland concentration was inoculated into Mueller-Hinton agar contained twofold dilutions of antibiotics. E-test (bióMeurieux, La Balme-Les-Grottes, France) procedure was reported previously, following manufacturer instructions [6]. Briefly, $100 \mu \mathrm{L}$ of $H$. pylori suspension with 3 McFarland standard was inoculated into Mueller-Hinton agar plate without antibiotic and one E-test strip were applied to the center of the plate. incubation under microaerophilic conditions for $72 \mathrm{~h}$. A full explanation of the method is available in the Additional file 1: Fig. S1.

\section{Statistical analysis}

The ADM is the gold standard for antibiotic susceptibility test, thus the results were used as the reference for validating the E-test method. The samples were grouped into "sensitive" and "resistant" according to the EUCAST clinical breakpoint criteria [16] and were then used to evaluate, essential agreement, Cohen's kappa analysis, McNemar, also the major and very major error rate between the two methods. The analysis was performed using the SPSS statistical software version 23.0 (IBM Corp., Armonk, NY, USA).

To better understand the agreement of the MIC results, we followed CLSI guideline EP-09 to use the non-parametric approach proposed by Bland and Altman with Krouwer modification because the gold standard is available $[17,18]$. Scatter plot and Passing-Bablok analyses were also performed using $\mathrm{R}$ environment ver. 3.5.1 with the mcr package [19]. Receiver operating characteristic analysis was used to evaluate the sensitivity, specificity, and area under the curve (AUC) of the E-test results relative to those of the ADM.

\section{Results}

\section{Susceptibility results of the ADM and E-test}

We initially attempted to culture 77 strains of $H$. pylori; however, five strains did not grow and were excluded. This growth failure number was still acceptable according to the U.S. Food and Drug Administration (FDA) recommendation for antimicrobial susceptibility testing [20]. Both the ADM and E-test were applied to the same 72 remaining strains.

In Table 1, both ADM and the E-test showed high resistance rates to metronidazole and levofloxacin. Slightly higher resistant rates were shown by the E-test for four antibiotics, but this difference was not statistically significant (McNemar test: amoxicillin, $P=0.99$; metronidazole, $P=0.55$; clarithromycin, $P=0.63$; and levofloxacin, $P=0.99$; the value for tetracycline could not be calculated because of the zero percentage result). MIC50 and MIC90 were the same for all the antibiotics except amoxicillin and tetracycline.

\section{Agreement of the susceptibility results}

To determine the precision and reliability of the E-test. Differences in the "sensitive" and "resistant" interpretations were further analyzed according to the agreement percentage and Cohen's kappa analysis (Table 1). The kappa values showed fair agreement for amoxicillin, moderate for clarithromycin, and substantial agreement for metronidazole and levofloxacin 
Table 1 Resistance rates according to the agar dilution method (ADM) and E-test

\begin{tabular}{|c|c|c|c|c|c|c|c|c|c|c|}
\hline \multirow[t]{2}{*}{ Antibiotic } & \multirow{2}{*}{$\begin{array}{l}\text { Clinical } \\
\text { breakpoint } \\
\text { (mg/L) }\end{array}$} & \multicolumn{2}{|c|}{ Resistance rate $(\%) \mathrm{n}=72$} & \multicolumn{2}{|c|}{$\operatorname{MIC50} 0^{a}(\mathrm{mg} / \mathrm{L})$} & \multicolumn{2}{|c|}{$\mathrm{MIC} 90^{\mathrm{a}}(\mathrm{mg} / \mathrm{L})$} & \multirow{2}{*}{$\begin{array}{l}\text { Essential } \\
\text { agreement } \\
(\%)\end{array}$} & \multirow{2}{*}{$\begin{array}{l}\text { Kappa } \\
\text { coefficient }\end{array}$} & \multirow{2}{*}{$\begin{array}{l}95 \% \text { confidence } \\
\text { interval }\end{array}$} \\
\hline & & ADM & E-test & ADM & E-test & ADM & E-test & & & \\
\hline Amoxicillin & $>0.125$ & $3 / 72(4.2)$ & 4/72 (5.6) & 0.032 & 0.016 & 0.064 & 0.125 & 93.1 & 0.25 & -0.38 to 0.88 \\
\hline Metronidazole & $>8$ & $30 / 72(41.7)$ & $33 / 72$ (45.8) & 8 & 8 & 64 & 64 & 84.7 & 0.69 & 0.52 to 0.85 \\
\hline Clarithromycin & $>0.5$ & $3 / 72(4.2)$ & $5 / 72(6.9)$ & 0.032 & 0.032 & 0.25 & 0.25 & 94.4 & 0.47 & -0.29 to 0.97 \\
\hline Levofloxacin & $>1$ & 18/72 (25.0) & 19/71 (26.4) & 0.25 & 0.25 & 8 & 8 & 93.1 & 0.81 & 0.66 to 0.97 \\
\hline Tetracycline & $>1$ & $0 / 72(0.0)$ & $2 / 71(2.8)$ & 0.125 & 0.064 & 0.5 & 0.25 & 97.2 & - & - \\
\hline
\end{tabular}

a MIC50/MIC90: minimum inhibitory concentrations that inhibited 50 and $90 \%$ of the isolates. For comparability with ADM, the upper limits were set as $1 \mathrm{mg} / \mathrm{L}$ for amoxicillin, $2 \mathrm{mg} / \mathrm{L}$ for clarithromycin and tetracycline, $8 \mathrm{mg} / \mathrm{L}$ for levofloxacin, and $64 \mathrm{mg} / \mathrm{L}$ for metronidazole, and the lower limits were set as $0.016 \mathrm{mg} / \mathrm{L}$ for amoxicillin, $0.032 \mathrm{mg} / \mathrm{L}$ for clarithromycin and tetracycline, $0.125 \mathrm{mg} / \mathrm{L}$ for levofloxacin, and $1 \mathrm{mg} / \mathrm{L}$ for metronidazole

prevalence by ADM. The kappa value for tetracycline could not be evaluated because of the zero value for prevalence.

\section{Measurement of errors}

Figure 1 shows the major errors and very major errors, as described in previous studies [13, 21, 22]. For all the antibiotics, the very major error rate was lower than the major error rate. Despite its low resistance rate according to both the ADM and E-test (4.2 and 5.6\%, respectively), amoxicillin was associated with a very major error rate of $2.78 \%$ and a major error rate of $4.17 \%$. Metronidazole also had a high very major error and major error rates (5.56 and 9.72\%, respectively).

\section{Analysis of agreement and systematic bias}

The modified Bland-Altman difference plots [17, 18] to assess the limit of agreement and any pattern of bias are shown in Fig. 2. For all the antibiotics except tetracycline, the median difference in measured MIC was zero, indicating there was no constant bias between the E-test and ADM. At low MIC values, the differences in the plots tended to clump around the median value, indicating precision between the methods. The error tended to increase at higher values of MIC for all the antibiotics, shown by the greater difference values. Spearman correlation analysis confirmed this correlation was significant for amoxicillin $(\mathrm{r}=0.53, P \leq 0.001)$, clarithromycin $(\mathrm{r}=0.56, P \leq 0.001)$, and tetracycline $(\mathrm{r}=0.76, P \leq 0.001)$.

As recommended by the CLSI, Passing-Bablok regression analysis was used to estimate the analytical method agreement and detecting the presence of any

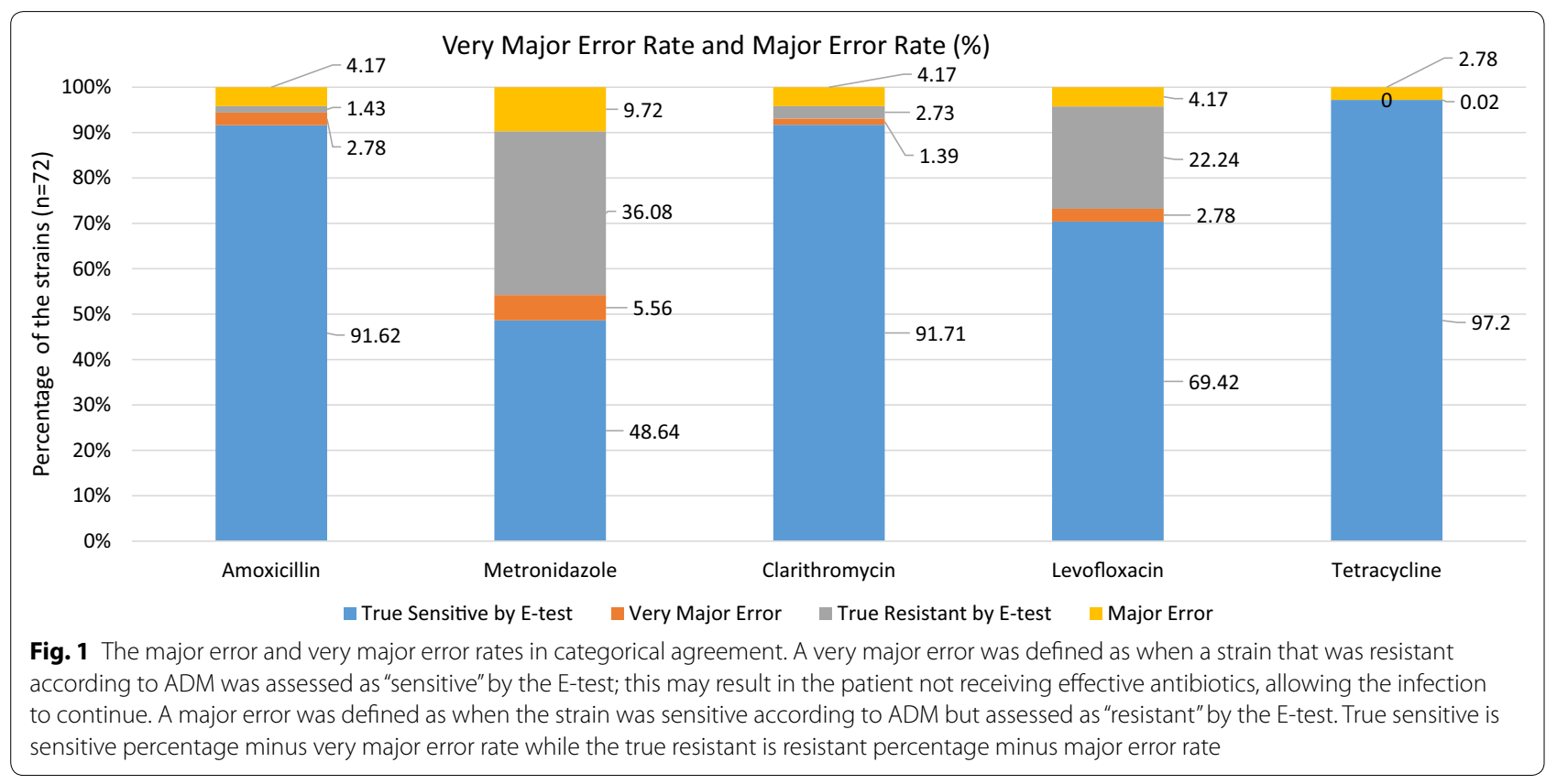



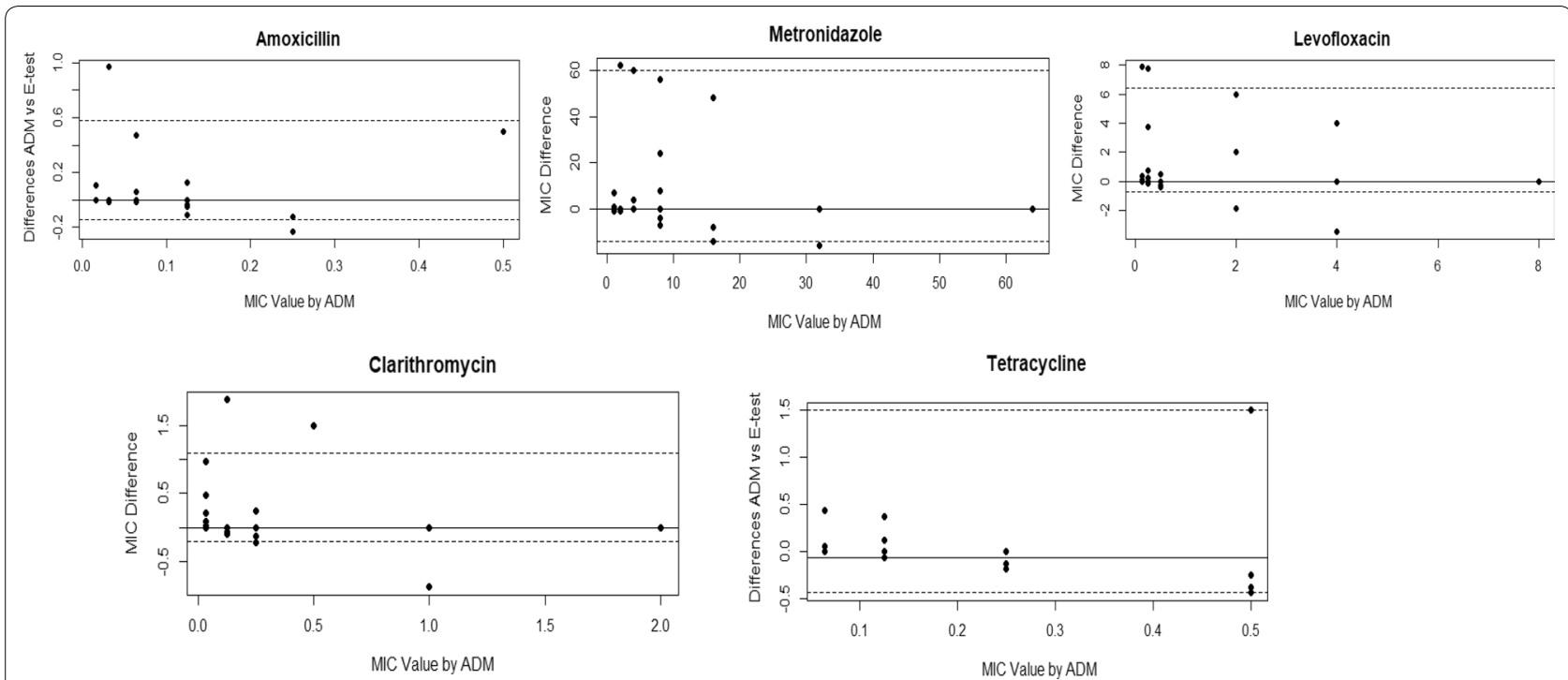

Fig. 2 Bland-Altman difference plots comparing the minimum inhibitory concentration (MIC) results of the agar dilution method and E-test for the five antibiotics. The plots use the modification of Krouwer $[17,18]$. The plots confirm that the measurements by both methods were equal for all the antibiotics, except for tetracycline. For tetracycline, the median difference was $0.061 \mathrm{mg} / \mathrm{L}$ bias. It can determine whether the E-test procedure and agar dilution method can be used interchangeably. In the Passing-Bablok regression plots (Additional file 1: Fig. S1), the confidence intervals for the intercepts for all the antibiotics except amoxicillin and tetracycline included zero, indicating there were no significant proportional differences between the values measured by the two methods. The confidence intervals for the slopes included the value 1 (indicating no significant difference between the measurements) for all the antibiotics except amoxicillin and tetracycline.

\section{Accuracy of the E-test}

The sensitivity, specificity, and AUC of the E-test for distinguishing the strains resistant to each antibiotic were calculated. For amoxicillin resistance, the E-test showed low sensitivity but high specificity (33.3 and 95.7\%), with a good AUC value (0.783). For clarithromycin, the sensitivity was also low (66.7\%) but the specificity and AUC were high (95.7 and 0.937\%, respectively). For metronidazole and levofloxacin, the E-test showed quite high sensitivity ( 86.7 and $88.9 \%$, respectively), specificity (83.3 and $94.4 \%$ ), and AUCs (0.887 and 0.919). It was not possible to make these calculations for tetracycline because ADM showed the resistance rate was zero.

\section{Discussion}

This is the first study to evaluate the validity of the E-test as an alternative method for the detection of resistant strains of H. pylori in Indonesia. E-test is preferable in clinical practice due to the lower cost and less time consuming [8]. Several previous studies have validated the E-test for European populations [21-23], Brazilian children [13] and American [24].

In this study, we found that the resistance rate obtained from E-test showed a slightly higher discrepancy compared to ADM, although this was statistically not significant according to McNemar analysis; similar to previous studies [23, 24]. For levofloxacin, metronidazole, and clarithromycin, the essential agreement was in the acceptable range according to the FDA $(>90 \%)$ with low major error and very major error rates [20, 25]. Agreement for MIC values with Bland-Altman and PassingBablok also showed that both methods can be used interchangeably with good sensitivity and specificity $[26$, 27].

However, consistent with other studies, metronidazole showed a low essential agreement and high very major error rate, but metronidazole resistance is common and is not a first-line treatment so its use is limited [2, 6, 22, 28]. The emergence of heteroresistance to metronidazole within a mixed colony may have played an important role in this result [24]. For amoxicillin, Cohen's kappa analysis only showed a fair agreement. Moreover, 
a non-significant correlation for Passing-Bablok and very low sensitivity might indicate the lower reliability of the E-test for measuring amoxicillin resistance, compared to other antibiotics. However, it also probably due to a very low prevalence of amoxicillin resistant thus limit the kappa analysis in estimating values, known as the "kappa paradox" [29]. Hence, amoxicillin is included in the first line regiment and the non-concordance that occurred may affect the treatment choice and patient's outcome [2].

The reason for the discrepancy observed in the E-test results was still unknown but is probably the result of several factors. The procedure for storing E-test strips may affect the drug concentration, and incubation in a microaerophilic environment may influence the activity of the antibiotic, especially for macrolides $[8,23]$. The large bacterial inoculum size was tested by an E-test strip while in ADM, small number of bacteria were inoculated on agar plates containing antibiotics. The difference in bacteria/antibiotics ratio may have resulted in higher growth capabilities of the strain, resulting in a higher measured resistance rate in the E-test than ADM. Indeed, it has previously been demonstrated that inoculum concentration has an impact on the discrepancies observed in microdilution and ADM [30].

In general, the E-test may overestimate the rates of resistance to antibiotics, but it may be applicable because it showed good agreement with ADM results for levofloxacin, metronidazole, clarithromycin, and tetracycline. However, the disagreement from amoxicillin may require further confirmation.

\section{Limitations}

One of the limitation of the present study was that no tests were performed in other laboratory centers to check the reproducibility of the methods. The isolates used in this study were collected in 2015 and stored in $-80{ }^{\circ} \mathrm{C}$. Even though the freeze storage effect on antibiotic sensitivity in $H$. pylori was varied between the studies [31-33], it may explain the discrepancy of MIC found in this study. The zero resistance rate for tetracycline also affected the analysis. The number of study samples met the recommendation of CLSI; however, a greater number may have improved the precision of the comparison. Nevertheless, the findings of this study provide the data that E-test was a simple but reliable diagnostic tool for antibiotic-resistant detection in $H$. pylori.

\section{Supplementary information}

Supplementary information accompanies this paper at https://doi. org/10.1186/s13104-019-4877-9.
Additional file 1. Methods explanation. Figure S1. Passing-Bablok regression of $A D M$ and E-test.

\section{Abbreviations}

ADM: agar dilution method; AUC: area under the curve; CLSI: Clinical and Laboratory Standards Institute; EUCAST: European Committee on Antibiotic Susceptibility Testing; FDA: U.S. Food and Drug Administration; MIC: minimum inhibitory concentration.

\section{Acknowledgements}

Not applicable.

\section{Authors' contributions}

YY, MM, and KAF conceived and designed the study; KAF, MM, LAW, DD, AFS, $N R, A K, I K A$ and $J A$ acquired and summarized the data; MM, KAF, and $Y Y$ analyzed the data; $d$ DD, IAN, PBS interpreted the data; KAF, MM, and YY wrote the paper; LAW and JA edited and revised the manuscript. All authors read and approved the manuscript.

\section{Funding}

This study was funded by grants from the National Institutes of Health (DK62813) and Grants-in-Aid for Scientific Research from the Ministry of Education, Culture, Sports, Science, and Technology (MEXT) of (15H02657, $16 \mathrm{H} 05191,16 \mathrm{H} 06279,18 \mathrm{KK} 0266$ and 19H03473) (YY) and the National Institutes of Health (DK62813). It was also supported by the Japan Society for the Promotion of Science Institutional Program for Core-to-Core Program; B. Africa-Asia Science Platform (YY). LAW, DD, and KAF are doctoral students supported by the MEXT Scholarship Program for 2015, 2016, and 2017, respectively. In addition, the Ministries of Research, Technology, and Higher Education in the World Class Professor Program (123.4/D2.3/KP/2018) supported this research (MM). The funding body had no role in the design of the study and collection, analysis and interpretation of data, and in writing the manuscript.

\section{Availability of data and materials}

The data sets used and/or analyzed during the current study available from the corresponding author on reasonable request.

\section{Ethics approval and consent to participate}

Written informed consent was obtained from all participants, and the protocol was approved by Dr. Cipto Mangunkusumo Teaching Hospital (Jakarta, Indonesia), Dr. Soetomo Teaching Hospital (Surabaya, Indonesia), Dr. Wahidin Sudirohusodo Teaching Hospital (Makassar, Indonesia), and Oita University Faculty of Medicine (Yufu, Japan)

\section{Consent for publication}

Not applicable.

\section{Competing interests}

The authors declare that they have no competing interests.

\section{Author details}

${ }^{1}$ Division of Gastroentero-Hepatology, Department of Internal Medicine, Faculty of Medicine-Dr. Soetomo Teaching Hospital, Universitas Airlangga, Jalan Mayjend Prof. Dr. Moestopo No. 6-8 Surabaya, Surabaya 60131, Indonesia. ${ }^{2}$ Institute of Tropical Disease, Universitas Airlangga, Surabaya 60115 Indonesia. ${ }^{3}$ Department of Environmental and Preventive Medicine, Oita University Faculty of Medicine, Yufu, Oita 879-5593, Japan. ${ }^{4}$ Division of Gastroenterology, Department of Internal Medicine, Faculty of Medicine, University of Indonesia, Jakarta 10430, Indonesia. ${ }^{5}$ Department of Internal Medicine, Faculty of Medicine Gadjah, Mada University-Dr. Sardjito, Yogyakarta 55281, Indonesia. ${ }^{6}$ Department of Community Nutrition, Bogor Agriculture University, Bogor 16680, Indonesia. ${ }^{7}$ School of Pharmacy, Bandung Institute of Technology, Bandung 40132, Indonesia. ${ }^{8}$ Global Oita Medical Advanced Research Center for Health, Oita University, Oita 870-1192, Japan. ${ }^{9}$ Department of Medicine, Gastroenterology and Hepatology Section, Baylor College of Medicine, Houston, TX 77030, USA.

Received: 7 November 2019 Accepted: 24 December 2019 Published online: 10 January 2020 


\section{References}

1. Sugano K, Tack J, Kuipers EJ, Graham DY, El-Omar EM, Miura S, et al. Kyoto global consensus report on Helicobacter pylori gastritis. Gut. 2015;64(9):1353-67

2. Malfertheiner P, Megraud F, O'Morain CA, Gisbert JP. Management of Helicobacter pylori infection-the Maastricht V/Florence Consensus Report. Gut. 2017;66(1):6-30.

3. Kuo YT, Liou JM, El-Omar EM, Wu JY, Leow AHR, Goh KL, et al. Primary antibiotic resistance in Helicobacter pylori in the Asia-Pacific region: a systematic review and meta-analysis. Lancet Gastroenterol Hepatol. 2017;2(10):707-15.

4. Savoldi A, Carrara E, Graham PDY, Conti M, Tacconelli E. Prevalence of antibiotic resistance in Helicobacter pylori: a systematic review and meta-analysis in World Health Organization regions. Gastroenterology. 2018;155(5):1372-82.

5. Kageyama C, Sato M, Sakae H, Obayashi Y, Kawahara Y, Mima T, et al. Increase in antibiotic resistant Helicobacter pylori in a University Hospital in Japan. Infect Drug Resist. 2019;12:597-602.

6. Miftahussurur M, Syam AF, Nusi IA, Makmun D, Waskito LA, Zein LH, et al. Surveillance of Helicobacter pylori antibiotic susceptibility in Indonesia: different resistance types among regions and with Novel Genetic Mutations. PLoS ONE. 2016;11(12):e0166199.

7. CLSI. Methods for dilution antimicrobial susceptibility test for bacteria that grow aerobically. 10th ed. Wayne: Clinical and Laboratory Standards Institute; 2015. p. M07.

8. Valdivieso-García A, Imgrund R, Deckert A, Varughese BM, Harris K, Bunimov N, et al. Cost analysis and antimicrobial susceptibility testing comparing the E test and the agar dilution method in Campylobacter jejuni and Campylobacter coli. Diagn Microbiol Infect Dis. 2009:65(2):168-74.

9. Clinical and Laboratory Standards Institute. Method comparison and bias estimation using patient samples; approved guideline. Wayne: Clinical and Laboratory Standards Institute; 2002. p. 2.

10. Lee G-B, Lee S-S, Lee W-b, Chang W-H. Automatic microfluidic system for antibiotic susceptibility testing and method of operating thereof. Google Patents. 2018

11. Tortorano AM, Viviani MA, Barchiesi F, Arzeni D, Rigoni AL, Cogliati M, et al Comparison of three methods for testing azole susceptibilities of Candida albicans strains isolated sequentially from oral cavities of AIDS patients. J Clin Microbiol. 1998;36(6):1578-83

12. Best LM, Haldane DJ, Keelan M, Taylor DE, Thomson AB, Loo V, et al. Multilaboratory comparison of proficiencies in susceptibility testing of Helicobacter pylori and correlation between agar dilution and $\mathrm{E}$ test methods. Antimicrob Agents Chemother. 2003;47(10):3138-44.

13. Ogata SK, Gales AC, Kawakami E. Antimicrobial susceptibility testing for Helicobacter pylori isolates from Brazilian children and adolescents: comparing agar dilution, E-test, and disk diffusion. Braz J Microbiol. 2014;45(4):1439-48.

14. Syam AF, Miftahussurur M, Makmun D, Nusi IA, Zain LH, Zulkhairi, et al. Risk factors and prevalence of Helicobacter pylori in five largest Islands of Indonesia: a preliminary study. PloS ONE. 2015;10(11):0140186.

15. Patel JB. Performance standards for antimicrobial susceptibility testing. Wayne: Clinical and Laboratory Standards Institute; 2017.

16. Eucast D. DocumentEDEF. 3.1. Determination of minimum inhibitory concentrations (MICs) of antibacterial agents by agar dilution. Clin Microbiol Infect. 2000;2000(6):509-15.

17. Bland JM, Altman DG. Measuring agreement in method comparison studies. Stat Methods Med Res. 1999:8(2):135-60.
18. Krouwer JS. Why Bland-Altman plots should use $X$, not $(Y+X) / 2$ when $X$ is a reference method. Stat Med. 2008:27(5):778-80.

19. Manuilova E, Schuetzenmeister A, Model F. mcr: method comparison regression. R package version 1.2.1. 2014.

20. Food U, Administration D. Class II special controls guidance document: antimicrobial susceptibility test (AST) systems; guidance for industry and FDA. Rockville: US Food Drug Adm; 2003.

21. Piccolomini R, Di Bonaventura G, Catamo G, Carbone F, Neri M. Comparative evaluation of the $E$ test, agar dilution, and broth microdilution for testing susceptibilities of Helicobacter pylori strains to 20 antimicrobial agents. J Clin Microbiol. 1997;35(7):1842-6.

22. Alarcón T, Domingo D, López-Brea M. Discrepancies between E-test and agar dilution methods for testing metronidazole susceptibility of Helicobacter pylori. J Clin Microbiol. 1998;36(4):1165-6.

23. Glupczynski Y, Broutet N, Cantagrel A, Andersen L, Alarcon T, Lopez-Brea $M$, et al. Comparison of the $E$ test and agar dilution method for antimicrobial suceptibility testing of Helicobacter pylori. Eur J Clin Microbiol Infect Dis. 2002:21(7):549-52.

24. Osato MS, Reddy R, Reddy SG, Penland RL, Graham DY. Comparison of the Etest and the NCCLS-approved agar dilution method to detect metronidazole and clarithromycin resistant Helicobacter pylori. Int J Antimicrob Agents. 2001:17(1):39-44.

25. Testing ECOAS. EUCAST guidelines for detection of resistance mechanisms and specific resistances of clinical and/or epidemiological importance. EUCAST, Basel, Switzerland. 2013. http://www.eucast.org/clini cal_breakpoints.

26. Bilic-Zulle L. Comparison of methods: passing and Bablok regression. Biochemia medica. 2011;21(1):49-52.

27. Passing $\mathrm{H}$, Bablok W. A new biometrical procedure for testing the equality of measurements from two different analytical methods. Application of linear regression procedures for method comparison studies in clinical chemistry, Part I. Clin Chem Lab Med. 1983;21(11):709-20.

28. Von Recklinghausen G, Ansorg R. Metronidazole susceptibility testing of Helicobacter pylori with the PDM epsilometer test (E test). Zentralblatt Bakteriologie. 1995:282(1):83-5.

29. Byrt T, Bishop J, Carlin JB. Bias, prevalence and kappa. J Clin Epidemiol. 1993:46(5):423-9.

30. Citron DM, Ostovari M, Karlsson A, Goldstein E. Evaluation of the $E$ test for susceptibility testing of anaerobic bacteria. J Clin Microbiol. 1991:29(10):2197-203.

31. Dore MP, Piana A, Carta M, Atzei A, Are BM, Mura l, et al. Amoxycillin resistance is one reason for failure of amoxycillin-omeprazole treatment of Helicobacter pylori infection. Aliment Pharmacol Ther. 1998;12(7):635-9.

32. Han SR, Bhakdi S, Maeurer MJ, Schneider T, Gehring S. Stable and unstable amoxicillin resistance in Helicobacter pylori: should antibiotic resistance testing be performed prior to eradication therapy? J Clin Microbiol. 1999;37(8):2740-1.

33. Mégraud F, Hazell S, Glupczynski Y. Antibiotic susceptibility and resistance. Helicobacter pylori physiology and genetics. United States: ASM Press; 2001

\section{Publisher's Note}

Springer Nature remains neutral with regard to jurisdictional claims in published maps and institutional affiliations. 